\title{
The role of interdiscursitity in learners' discussion when writing a formal letter
}

\author{
Daljeet Singh Sedhu ${ }^{1, *}$ and Raja Nor Safinas Raja Harun ${ }^{2}$ \\ ${ }^{1}$ Department of Social Science and Hospitality, Tunku Abdul Rahman University College. \\ ${ }^{2}$ Faculty of Languages and Communication, Universiti Pendidikan Sultan Idris.
}

\begin{abstract}
Writing is the foundation of real formal task which allows writers to engage in real communication outside the classroom. Thus, formal letter writing is a range whereby learners get engaged in a wide range of writing tasks not limited to corrective facts but also the language used outside of the classroom. This study emphasises on the use of interdiscursivity through learners' group discussion when writing a formal letter. A qualitative method was employed in this study whereby the participants' discussions on the process of formal letter writing were recorded. The recordings were then transcribed and analysed. The transcriptions revealed how interdiscursivity could be used as an efficient strategy for formal letter writing. The findings of this study can aid academicians in devising instructional strategies and materials for the teaching of writing formal letter writing. This study implicates that interdiscusivity has a role in learner's discussion when writing a formal letter.
\end{abstract}

\footnotetext{
* Corresponding author: daljeetsingh@tarc.edu.my
} 


\section{Introduction}

Major conformist models of language teaching have been found to be inadequate to address the current interdisciplinary anxieties and practices in the field (Bhatia \& Anthony, 2017). Several learners who enrol in institutions of tertiary learning have lack of prior knowledge in writing, native and non-native speakers of English alike (Macbeth, 2006). Learners face difficulties in many aspects of their writing skill such as the use of proper grammar, punctuation, capitalisation, vocabulary, and even the fundamental aspects of initiating writing, which is also a challenging task of output for both educators and learners in ESL classes (Ghabool \& Kashef, 2012). The authors confirm that the lack of English language proficiency is the leading source of difficulty that Malaysian ESL learners face in their writing tasks. Prospective employers often commented that despite being academically excellent, Malaysian graduates lack soft skills, particularly communication and logical-thinking skills (Ngang \& Chan, 2015).

In extension to the above argument, tertiary learners were found to have lack of vocabulary to explain their writing tasks in the form of sentences (Halim, Ahsan \& Munir, 2011). Formal letter writing is a field whereby learners get engaged in a wide range of writing tasks that require corrective facts of the language. Shafie and Nayan (2010) state six problems faced by novice writers: (i) inability to work together with associates, (ii) low language proficiency, (iii) inadequate time to discuss, (iv) limited research skills, (v) lack of ideas and (vi) pressure during two-way writing.

Since the researchers have been lecturing in higher learning institutions for more than ten years, we have observed that learners are not familiar with the context and content of formal letter writing when introduced to them. Learners are unable to understand written features of some of the expert genres, and they are still inexperienced in the discursive realities of the professional world (Bhatia, 2016).

Interdiscursivity is the characteristic of discourse that relates to other discourses. Fairclough (2003) prefers the concept 'orders of discourse' which means it is often an analytic concept. Interdiscursivity has close affinity to recontextualisation because interdiscourse often implies that elements are imported from another discourse. The meaning of interdiscursivity varies and it can be divided into three levels.

Firstly, Courtine (1981) refers interdiscursivity as a discourse which has a relation to another discourse, a meaning which is close to the meaning of intertextuality. Secondly, Linell (1998) refers interdiscursivity as a relation between types of discourse such as genres. Thirdly, Fairclough (2003) refers interdiscursivity as relations between discursive formation that is between large heterogeneous discursive entities, which can be related to natural arguments and oral communication. In this study, Faircloughs' (2003) definition of interdiscursivity will be used to look into the diverse oral communication between students. 
In this study, the researchers focused on learners' knowledge in formal letter writing of the academic discourse. Knowledge in the ESL writing of formal letter discourse is fundamental to the learners' academic survival, as it is important in assessing the learners' academic progress. As learners of ESL, writing a formal letter has often been central to the discussions on this subject. The researchers, thus, considered that it is vital to focus on the interaction practices in which learners participate in the writing process. These practices can provide insights into developing a potentially effective academic writing model for learners. As such, the researchers attempt to find out how the use of interdiscursivity through learner-learner interaction in a group discussion can assist learners in writing a formal letter.

\section{Objective and Research Question}

\subsection{The objective of this study is:}

To study the role of interdiscursivity in learners' interaction when writing a formal letter.

2.2 The research question that underpins this study is:

How does the role of interdiscursivity through learner-learner interaction in a group discussion assist learners when writing a formal letter?

\section{Methodology}

The research method used in this study was document analysis. Transcriptions of learners' discussions during the formal letter writing tasks were analysed. A qualitative analysis method was used to find out how interdiscursivity could support learners when writing a formal letter through learner-learner interaction. The purpose of using this method is to enable the researchers to answer the research question as stated in this study.

The details of how the research instruments were used to collect data are explained further in this section. First, the students were divided into six groups and each group consisted of four members. Each group was given the same task that was to write a formal letter based on the outcomes of their group discussion. Secondly, each group was told to do a voice recording of their discussion from the moment they started attempting the task until it was completed. The recordings of the discussions were between 10 to 15 minutes. The recordings were then collected by the researcher to be transcribed for an in-depth data analysis purpose. The transcriptions were analysed to observe the process of learner-learner interaction in each group. This was done to determine how interdiscursivity could be used by learners to assist them in writing a formal letter. The main areas that were looked into were enquiries, negotiations, agreements and disagreements, and clarifications done by each of the group members.

Each group was required to engage in a discussion pertaining to the task given before they started writing the formal letter. The task given was for them to a write a formal letter to conduct a charity fund raising event on behalf of a society. The outcomes of the discussion will be the learners' interaction with each other and their discursive arguments towards learning. Interaction and discursive arguments are linked because when learners interact with each other, they will voice out their opinions related to the given task. These learners 
presented their agreements and disagreements of each other's discursive arguments. In other words, interdiscursivity was evident in the learner-learner interaction.

\section{Findings and Discussions}

Research Question: How does the role of interdiscursivity through learner-learner interaction in a group discussion assist learners when writing a formal letter?

Based on the document analysis, there were emerging themes on the role of interdiscursivity through learner-learner interaction, which can assist learners when writing a formal letter. These are detailed as follows:

\subsection{Discursive Understanding of the Task}

The learners developed a discursive understanding of the task given to them during the course of the discussions. At the beginning of the discussions, it was apparent that they were confused about the task prerequisite. In an attempt to address this confusion, they engaged in debates and resorted to linguistic adaption during their discussions. They learnt to modify ideas to fit the requirement of the given task. They became conscious of what they learned, more focused on completing the task and not on language use, used the Internet to search for ideas, and developed diverse ideas in the discussions.

Each of the learners had their discursive understanding after reading the task given. They gave their views on the task given to them. This can be seen in the following excerpts:

Learner F: "From my point of view, we should choose which society to be represented before we think of the fundraising. I think by doing this, we can decide what kind of activity we can plan for the fundraising."

Learner N: "After I have read the question, I think let's look into what activity we come up for the fundraising then think of a society. It does not matter of taking any society to conduct this activity."

Each learner came up with their individual idea of completing the task given to them. They shared with each other their point of view and discussed among themselves how to incorporate everyone's ideas to suit the requirement of the task. It is essential to analyse each learner's ideas critically as this will help learners to stay on topic. This will also help teachers to easily identify and correct the discursive views given by learners by providing immediate feedback. This supports the findings of Bakhtin (2010) in which he argues that utterances in a language are always dialogised, and this changes based on how a reader interprets what they read and after that describe what they have understood through verbal discussion.

\subsection{Confusion of Task Requirement Through The Discussion Process}

Learners became confused with the spoken genre when they communicated with other group members. One member might influence others to stray away from the task requirement, as demonstrated in the following excerpts: 
Learner C: "I think we can plan fundraising as a secondary event, let us focus on another event that will be benefit for the Society to organise".

Learner A: "We should have two different dates for the event so that we can gain more money. We write the formal letter to mention we want do this event and tell the participants to register then later we will inform them about the particulars if it is confirmed."

It is crucial for learners to synthesise what they read in order to fulfil the requirement of the task. The act of misleading by one group member may cause the whole group to produce an out of topic formal letter, which did not fulfil the task requirement. Each member should play their roles to ensure that every group member gets a proper understanding of the task given to them. This supports the finding of Bakhtin (2010) in which he states that the relationship of genre involved in the mixing, in a way, can cloud a clear distinction and may perhaps mislead the action of the doer of a task. Corresponds as this is a "primary genre' as mentioned by Bakhtin (2010), which means that oral dialogue distinguisher to the listener of how the speaker presents the definition of genre discussed. He elaborates by saying that the speaker might also produce a different definition when they speak of what they have read from any text genre and present an idea based on their understanding and interpretation. This is known as 'secondary genre'. This also supports the findings of Wu (2011) whereby in some specific cases it is the mixing of discourses or styles that makes sense in the formation of interdiscursive relations.

\subsection{Negotiation and Linguistic Alteration}

Learners negotiated with each other on the points to be included in the formal letter. They gave their ideas and negotiated with the group members for their ideas to be included in the formal letter. This was revealed in the following excerpts:

Learner M: “ I think we should have an event like Canteen Day and have other special events like lucky draw, clown performance and much more for this fundraising, what do you think of my idea?"

Learner F: "I think the event should be organised on a weekend or public holiday which will be easier for everyone to attend as I think this event should open to all public."

Learners were able to use proper vocabulary through negotiation among group members. This allowed members to think of the rational way of writing the content of a formal letter and lead them to write more creatively. This supports the findings of $\mathrm{Wu}(2011)$, whereby interdiscursivity can also act as a product of dynamic negotiation, indicating the process of making a linguistic choice. Here, the doer of a task will use negotiation to voice out his or her opinion so as to allow listeners to think rationally before accepting the views and ideas directed at them. According to Verschueren (2015), language is adjustable from our daily use of language in the process of learning. Interdiscursivity, thus, enables the speakers to convey the message to the listeners by strengthening the ideas and opinions delivered, eventually leading to a successful communication.

\subsection{Revision of Ideas}


Learners constantly revised the ideas they had initially conveyed as the discussion went on. They tended to refer to what they had written down earlier in the formal letter and changed them to relate to the new points written in the content of the formal letter. The following excerpts illustrate this revision of ideas.

Learner A: "I think we should look back at the number of programmes involved in this fundraising event. From my point of view, it should not have too many programmes."

Learner E: "We should see whether these programmes can be conducted in this venue. Otherwise, we need to reconsider of a different idea for this formal letter."

Learners often looked back at the content of a formal letter that they had written to check whether the points were coherent, and to match the points in the content with one another. This allows learners to understand the changes needed in ensuring that a formal letter can be used as a successful communication tool to avoid confusions among readers. This process is known as "hybridisation" (Bakhtin, 2010), in which changes take place in the task when there is an on-going discussion. This all depends on the speaker's utterance by noticing that there is a need for changes to be done and notifying the listeners to identify the changes. Marchenkova (2005) mentioned that people normally reinterpret what they have uttered or heard earlier into giving it a meaningful definition so as to achieve successful communication.

\subsection{Sensible of Learning}

Learners were able to recall and connect the discussion to their social context. The discussion on the content of the formal letter by these learners was often based on their personal experience. This is apparent in the following excerpts:

Learner C: "Let's have this fundraising by having recycling campaign. When I was in my secondary school, we did a fundraising activity by doing recycling campaign, and we gained much money by selling old newspapers, aluminium cans and other recycling products."

Learner G: "I think we should have something like a Family Day and invite all the parents of the learners to come and participate in this event. I have seen many this kind of activities work well."

Learners often participated in a discussion by placing the topic in their social context; a simple example is by relating the topic to their personal experience. Kubli (2005) mentioned that consciousness of learning is based on the exchange of ideas among learners. In a learner-learner interaction, every word used is based on the learners' exposure limit within their personal social context. Such exchange of knowledge is considered as interdiscursivity in which Bakhtin theory could be matched with the mentioned process (Kubli, 2005). According to Kuo and Lin (2015), this way also encourages learners to participate independently, thus enabling them to manage a learning process on their own without the aid of a teacher.

\subsection{Attentive on Task and not on Language}


Learners were more focused on completing the task at the expense of language precision, as revealed in the following excerpts:

Learner L: "I think we have misspelled a few words in this letter, but let's look at it later, we think on how to complete it first."

Learner M: "I do not think it is necessary to see what words important to be used in this formal letter task, we focus on finishing otherwise we will not have enough of time."

Learners concentrated less on producing a formal letter that follows grammatical rules accordingly. They were more focused on trying to complete the task. This supports the findings of Mathews and Jacquet (2013) that learners can convey their ideas anonymously and focus on the content of a writing task. They can, in fact, achieve a successful communication despite the lack of grammatical precision.

\subsection{The Idea of Using the Internet}

Students came up with the idea of using a computer to complete the formal letter writing task. They preferred using a computer with an Internet connection to complete the task. This is evident in the following excerpt:

Student F: "I think it will be better if we could use the computer. We can find more information and discuss among ourselves with different ideas."

Students preferred using a computer to complete a discussion-based task. It is convenient for them to gather different ideas from each member by using the Internet. Smith (2005) mentioned that computer could enhance students' competence in reading and allow them to convey ideas effectively. He also suggested that students should be encouraged to use a computer for them to write more and produce more creative output. Mathews and Jacquet (2013), however, highlighted the need for computer-literate instructors too, without whom the interactive and collaborative tasks made possible with the use of computers, will be rendered useless.

\subsection{Improved the Ability to Speak Based on Task Given}

Students were able to improve their ability to speak to each other in a group discussion. They overcame factors such as shyness and unwillingness to speak as elucidated in the following excerpts :

Student D: "I feel more confident to speak in this kind of group discussion. I can listen to everyone's idea and try to think how to relate to other points."

Student O: "I prefer to do this way of discussion because it helps me to speak out what I feel like sharing with everyone." 
Students were able to freely voice their opinions when interacting with other group members, thus building their confidence to communicate. They were also able to improve their communication skills, hence allowing them to think critically of other group members' ideas and to give comments. This finding echoes that of a research done by Javid (2014), in which he found that by using learner-learner interaction as a strategy in a learning process, the student will be able to develop their own mode of learning. Furthermore, this can be used as an aid for students to learn a second language such as the English language. Javid (2014) too proposed that students often find it much easier to express themselves verbally in front of a small group when learning to work in a group. By using this strategy in a learning process, it will also improve students' interpersonal communication skills (Lee, 2017).

\subsection{Diverse Communication}

Students conducted brainstorm session to develop ideas for the content of the formal letter. The group leaders in each group decided to choose this strategy to get every member to participate in the discussion so as to complete the task given, as evident in the following excerpt:

Student P: "Let's sit around and discuss the content of the formal letter. I suggest we do brainstorming on the points that can be written for the formal letter."

The students used brainstorming as a part of their discussion process in completing the formal letter writing task. This can be considered as an aspect of group dynamics role in a classroom interaction. The group leaders were able to provide guidelines and helped the members to maintain their energy and interest to participate in the discussion process. These findings also support the statement by Curry, Jiobu and Schwirian (2005) that there are few characteristics must be shown by a group leader that is authoritarian, style of communication shown and being democratic to each member in a group. A circular arrangement of a group is adaptable because it assists the best interaction among members during the discussion as mentioned by Winston and Patterson (2006).

\section{Conclusion}

The purpose of this study is to determine the use of interdiscursivity through learner-learner interaction among tertiary-level learners when writing a formal letter.

Most of the time, learners do not understand what they are writing in a formal letter because they do not know the structures and conventions involved in formal letter writing. Improving formal letter writing is a big challenge for both teachers and learners. Many teachers may feel that there are many challenges in implementing effective formal letter writing based on the past studies discussed in Section 1.0. As for the learners, there are various strategies available for them to learn yet it takes time for them to be able to apply the appropriate strategy to a specific writing task. Thus, their motivation to write and their discursive ideas are limited. It is the researcher's opinion that efforts should be directed towards supporting interdiscursivity through learner-learner interaction among tertiary level learners when writing a formal letter. 
Future research on using interdiscursivity as a strategy for writing skills should not only focus on the result of this group discussion. The emphasis should be on the process of learning as learners would be able to use the social and learning skills, acquired through interdiscursivity, in their everyday life.

As such, it can be surmised that it is vital for future researchers to continue their efforts in promoting interdiscursivity as an alternative learning strategy and maximising its potential as an instructional intervention.

\section{References}

Bakhtin, M. M. (2010). Speech genres and other late essays. University of Texas Press.

Bakhtin, M. M. (2010). The dialogic imagination: Four essays (Vol. 1). University of Texas Press.

Bhatia, V. K. (2016). Critical genre analysis: Investigating interdiscursive performance in professional practice. Taylor \& Francis.

Courtine, J.-J. (1981). Analyse du discours politique. Paris: Langages.

Curry, T. J., Jiobu, R. M., \& Schwirian, K. P. (2005). Sociology for the twenty-first century. Pearson College Division.

Fairclough, N. (2003). Analysing discourse: Textual analysis for social research. Psychology Press.

Ghabool, N., \& Kashef, S. H. (2012). Investigating Malaysian ESL students' writing problems on conventions, punctuation, and language use at secondary school level. Journal of Studies in Education, 2(3), 130-143.

Javid, C. Z. (2014). Perceptive determination of Saudi EFL learners about the characteristics of an ideal English language teacher. Research on Humanities and Social sciences, 4(8), 42-53.

Kubli, F. (2005). Science teaching as a dialogue-Bakhtin, Vygotsky and some applications in the classroom. Science \& Education, 14(6), 501-534.

Kuo, K. Y. C., \& Lin, C. S. (2015). Studies on Patterns and Variations of Learning Community of Practices in Global Context. In Learning and Teaching in Computing and Engineering (LaTiCE), 2015 International Conference on (pp. 176-179). IEEE.

Lee, M. K. (2017). To Be Autonomous or Not to Be: Issues of Subsuming

Self- Determination Theory Into Research on Language Learner Autonomy. TESOL Quarterly, 51(1), 220-228.

Linell, P. (1998). Approaching dialogue: Talk, interaction and contexts in dialogical perspectives (Vol. 3). John Benjamins Publishing.

Marchenkova, L. (2005). Language, culture, and self: The Bakhtin-Vygotsky encounter. Dialogue with Bakhtin on second and foreign language learning: New perspectives, 171-188. 
Mathews, T. J., \& Jacquet, R. C. (2013). Using Strategic Interaction in L2 Writing. American Association of Teachers of Spanish and Portuguese.

Ngang, T. K., \& Chan, T. C. (2015). The importance of ethics, moral and professional skills of novice teachers. Procedia-Social and Behavioral Sciences, 205, 8-12.

Halim, N. B. A., Ahsan, N. I. A., \& Munir, F. A. (2011). Writing Final Year Project Report in English: Problems, Motivating and Hindering Factors among UTeM Final Year Engineering Learners. Asian Social Science, 8(1), p27.

Shafie, L. A., \& Nayan, S. (2010). Employability awareness among Malaysian undergraduates. International Journal of Business and Management, 5(8), 119.

Smith, R. O. (2005). Working with difference in online collaborative groups. Adult Education Quarterly, 55(3), 182-199.

Verschueren, J. (2015). Ideology in discourse. The International Encyclopedia of Language and Social Interaction.

Winston, B. E., \& Patterson, K. (2006). An integrative definition of leadership. International Journal of Leadership Studies, 1(2), 6-66.

Wu, J. (2011). Understanding Interdiscursivity: A Pragmatic Model. Guangzhou: University of Cambridge. 